\title{
A NEW GENUS OF THE TRACHYSPHYRUS GROUP FROM SOUTHERN BRAZIL (HYMENOPTERA, ICHNEUMONIDAE)*
}

\author{
By Charles C. Porter
}

\author{
Biological Laboratories, Harvard University
}

The author has completed a revision of the South American species of the mesostenine genus Trachysphyrus Haliday (scheduled to be published during 1967 as a Memoir of the American Entomological Institute). In the course of this study there were discovered a few small groups of species definitely related to Trachysphyrus but apparently distinct enough to warrant recognition as separate genera. Some of these genera have already been described (Porter I963, i965). Several more, limited to the Chilean faunal region, are currently in manuscript and will be published as a unit at a later date. The present contribution treats an isolated and aberrant form known only from the southern Brazilian states of Santa Catarina and Rio Grande do Sul.

Nelophia, new genus

Flagellum: female: definitely flattened below toward apex, ist segment 6.I-6.5 as long as deep apically; male: segments of about proximal $3 / 4$ with dense, erect setae beneath only for a short distance near base and apex, of distal I/4 with progressively more extensive erect setae below; ist segment 4.0 as long as deep apically. Front: unarmed, only weakly excavated. Ocellar Area: only slightly raised. Clypeus: rather low, blunt, asymmetrically subpyramidal in profile, gently and a little convexly sloping upward to near apex and then more steeply and a little concavely declivous; apical margin slightly convex. Mandible: $\mathbf{2 . 5 - 2 . 7}$ as long as wide across base of teeth; teeth subequal. Occipital and Hypostomal Carinae: occipital carina moderately low above, becoming a rather high flange laterally, lower again close to juncture or near-juncture with hypostomal carina; hypostomal carina very high, about I/4-I/3 as high as basal width of mandible, rather concave and scoop-shaped. Pronotum: dorsal margin a little swollen, with a shallow and obscure submarginal groove; epomia a long, sharp, oblique carina in scrobe, much weaker and prolonged only a short distance below, not defining a discrete swelling or lappet-like area above; anterior margin rounded-off or

\footnotetext{
*Manuscript received by the editor May 11, 1967
} 

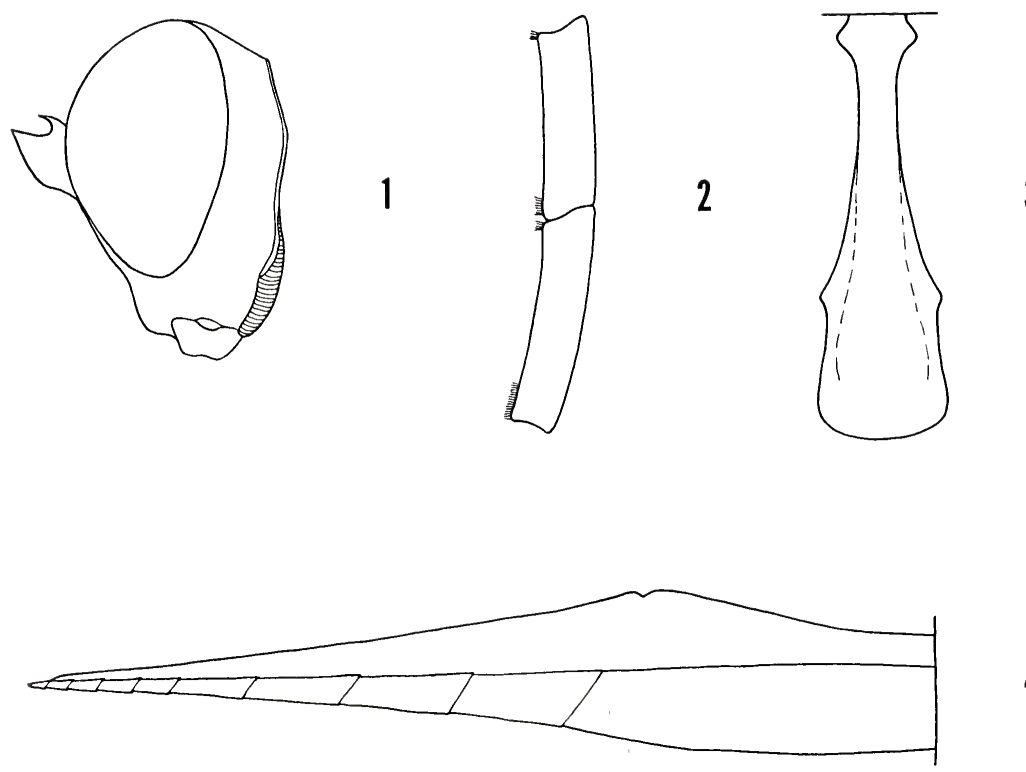

Figure 1. Nelophia compsa. Side view of female head.

Figure 2. Nelophia compsa. First two flagellar segments of male.

Figure 3. Nelophia compsa. Dorsal view of female first gastric segment.

Figure 4. Nelophia compsa. Side view of ovipositor tip.

weakly angled toward mid-height laterally. Notauli: rather shallow and narrow, traceable $\mathrm{I} / 2$ or a little more the length of mesocutum. Mesopleuron: subalarum a little swollen, not especially expanded; only a very tiny carina on prepectus near hind-corner of pronotum. Wing-Venation: radial cell $4 . \mathrm{I}-4.2$ as long as wide, about $\mathrm{I} / 3$ its length removed from tip of wing; areolet moderately large, rather high, intercubiti strongly converging above, 2nd abscissa of radius 0.4-0.6 as long as Ist intercubitus; 2nd recurrent approximately vertical, almost straight or slightly curved on upper I/2; disco-cubitus gently curved to weakly angled, a short to moderately long ramellus near middle; nervulus interstitial to antefurcal; mediella slightly arched in female, a little more definitely arched in male; upper part of nervellus in female I.6-2.0 as long as lower, in male I.I; axillus close to hind-margin of wing. Propodeum: spiracle 2.0-2.5 as long as wide; slightly elongate in profile (a little more elongate in male), 
basal face gently arched and weakly sloping behind, apical face as long as basal and quite steeply declivous; basal trans-carina mostly fine and sharp but somewhat irregular medially and laterally, more generally weak and irregular but traceable in male; apical transcarina wanting, except for the rather large and conspicuous subligulate to ligulate cristae; median and lateral longitudinal carinae vague or absent; pleural carina weak and irregular. Ist gastric segment: in both sexes with a large, bluntly triangular lateral expansion at base of petiole; petiole long and slender; postpetiole only weakly expanded, O.9-I.O as wide apically as long from spiracle to apex in female, 0.8 in male; petiole without distinct longitudinal carinae or with only a trace of dorso-lateral and dorsal carinae, especially near apex; postpetiole with ventro-lateral longitudinal carina strong, dorsolateral carina weakly suggested, and dorsal carinae vague or absent. 2nd gastric tergite: in both sexes with mostly superficial punctation and largely well-separated setae. Gaster: unusually long and slender fusiform, somewhat compressed toward apex. Ovipositor: sheathed portion 0.3-0.4 as long as fore-wing; straight, moderately slender, strongly compressed; nodus distinct, with a small, sharp notch; dorsal valve with a long, almost direct taper between notch and apex; ventral valve on tip with fine, well-spaced, oblique ridges; tip 0.19-0.22 as high at notch as long from notch to apex.

Type Species: Nelophia compsa, new species.

Discussion: Nelophia belongs to the subtribe Mesostenina of the geline tribe Mesostenini, as defined by Townes and Townes (I962, pp. 7, 32-33). Here its weakly arched mediella, elongate propodeal spiracle, and large, dorsally narrowed areolet all suggest a close relationship to Trachysphyrus. From Trachysphyrus Nelophia differs most strikingly because of its more slender habitus (in female), apically flattened female antenna, discontinuous erect setae of male flagellomeres, very high and scoop-shaped hypostomal carina, large expansion at base of petiole, essential absence of longitudinal carinae on petiole, and slender female postpetiole. This is a combination of characters unapproached by any known South American species of Trachysphyrus, although some of these features are found singly in a few widely separated species representing diverse phyletic lines within that genus.

The closest relatives of Nelophia are probably in the complex subandean and pampal north-central Argentine radiation of the genus Trachysphyrus, particularly among certain as yet undescribed forms of the Albitarsis Species Group. This genus may thus be interpreted 
as an aberrant subtropical offshoot of a basically temperate assemblage.

Generic Name: Nelophia is derived from the Greek ne-, a negative prefix, and lophia, a "crest" or "ridge".

\section{Nelophia compsa, new species}

Figures I-4. Map I.

Types: Holotype: (female) brazil (Santa Catarina: Nova Teutonia, October 1964, Fritz Plaumann) (Museum of Comparative Zoology, Cambridge, Mass.). Paratypes: (2 females and I male) BRaZIL (Santa Catarina: Nova Teutonia, 300-500 m., January 8, 1953, Fritz Plaumann; Rio Grande do Sul: Pelotas, October 9, 1956, C. Biezanko) (Canadian National Collection, Ottawa, Canada; Michigan State University, East Lansing, Mich.).

Female: Color: antenna black, more or less brownish-stained below toward apex, a ventrally more or less incomplete white annulus on flagellomeres 5 (apex) to I I or I2 (in part); head, mesosoma, and gaster black, rather dully pale reddish more or less as follows: often on many cephalic and thoracic sutures; toward lower hind-corner of mesopleuron; more broadly on lower or apical $\mathrm{I} / 2$ of metapleuron; often slightly on propodeum margining apical white bars; on Ist gastric segment broadly below and laterally and somewhat above near base and often subapically; and sometimes a little subapically and on thyridial region of 2nd gastric tergite; the following white: about basal I/ 2 of mandible; very large blotch on clypeus; most of face; orbits - narrowly interrupted opposite anterior tentorial pit, broadened below in front to fuse with white on face, and broadened below behind to include almost all of malar space; broad anterior margin of pronotum except near apex; broad dorsal margin of pronotum except on median $\mathrm{I} / 3$ and sometimes near apex; tegula; subalarum; short bar on mesoscutum just above and in part a little behind tegula; about anterior $2 / 3-3 / 4$ of scutellum; more or less of postscutellum; very large blotch on mesopleuron; hind-margin of mesopleuron; most of metanotum laterally; large blotch on apical I/2 of metapleuron; small (sometimes vague) to large blotch in laterobasal area and elongate blotch on hind-face of propodeum, from crista (inclusive) to apex; broad apical band and sometimes more or less fragmented lateral stripe on Ist gastric segment; broad lateral and somewhat narrower apical (subapical or sometimes wanting on 2nd tergite) bands on tergites 2-4; and narrower apical bands, becoming much broader laterally, on succeeding tergites; fore-coxa 
pale red, broadly white-blotched anteriorly, more or less darkened exteriorly above behind white blotch; fore-trochanter and femur pale yellowish red-brown, fore-tibia and tarsus more yellowish; mid-coxa and trochanter pale red, coxa with a moderately large white blotch above anterolaterally; mid-femur blackish with red-brown staining, especially basad, apicad, and within; mid-tibia and tarsus yellowish; hind-coxa, trochanter, and narrow base of femur pale reddish, femur mostly black, tibia and tarsus yellow; wings hyaline, with a small whitish area at base of stigma. Length of fore-wing: 8.3-9.2 mm. Malar Space: 0.7-0.8 as long as basal width of mandible. Temple: 0.4 as long as eye in dorsal view; strongly and aimost directly receding; smooth and shining laterally with sharp, medium-sized punctures separated in general by little more to not much less than their diameters, punctures becoming larger, denser, and stronger behind and, especially, above where they are reticulately confluent. Fore-tibia: moderately stout, scarcely inflated. Mesoscutum: shining with some micro-reticulation and with large, strong, adjacent to reticulately confluent punctures and quite strong trans-biased wrinkles along notauli (mostly within) and with more irregular wrinkling over a large area behind terminus of notauli. Mesopleuron: speculum swollen, shining, often largely invaded by strong punctures and wrinkles;



Map 1. Localities for Nelophia compsa. 
surface otherwise moderately strongly reticulately wrinkled. Propodeum: rather strongly reticulately wrinkled, except more weakly sculptured basad of basal trans-carina. Ist gastric segment: postpetiole finely to rather strongly and granularly micro-reticulate but becoming smooth and polished apicad, with scattered, small, shallow punctures emitting moderately long, not much overlapping setae mostly apically and laterally. 2nd gastric tergite: mat to dully shining, finely and granularly micro-reticulate with scattered small to medium-sized, mostly superficial punctures emitting long, rather irregularly spaced setae that average a little to very much shorter than their interspaces. Gaster: setae of following tergites more or less consistently overlapping, much denser than on 2nd. MALE: Color: differs from female as follows: flagellum less definitely brownish-stained, with a more or less incomplete white annulus on segments I I (in part) or I2 to I8 or I9 (basally); reddish staining a little duller and less extensive; white blotch on clypeus larger and mostly fused with white on face; white band of dorsal margin of pronotum reaching from opposite end of notaulus only about $2 / 3$ the distance to tegula; white on mesopleuron broken up into a large blotch on lower I/2 anteriorly and a smaller, detached blotch in hind-corner; apical margin of mesopleuron more dully whitish; no white laterally on Ist gastric segment; lateral and apical white bands on tergites 2-4 narrower, subapical band on 2nd especially narrow and brownishsuffused; fore-coxa black with piceous staining and broadly white anteriorly; fore-trochanter whitish below; white blotch on mid-coxa much smaller; hind-legs broken off beyond coxa. Length of forewing: $8.4 \mathrm{~mm}$. Malar Space: 0.7 as long as basal width of mandible. Temple: 0.5 as long as eye in dorsal view. Gaster: slender, compressed toward apex, setae about as in female.

Specific NAME: Compsa is derived from the Greek adjective kompsos, which means "elegant" or "pretty".

Porter, C. C.

\section{REFERENCES}

1963. A New Genus of the Tribe Mesostenini from Chile (Hymenoptera, Ichneumonidae). Psyche 70(2): 117-119.

1965. Picrocryptoides: A New Genus of the Tribe Mesostenini from Southern South America (Hymenoptera, Ichneumonidae). Psyche $72(2): 167-174$.

Townes, H. K. And M. Townes.

1962. Ichneumon Flies of America North of México: 3. Subfamily Gelinae, Tribe Mesostenini. Bull. U. S. Nat. Mus. 216. Pt. 3. 


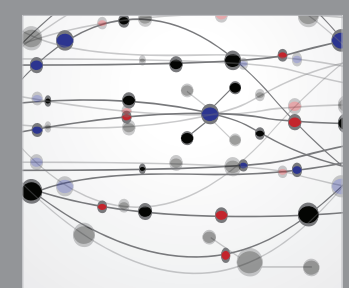

The Scientific World Journal

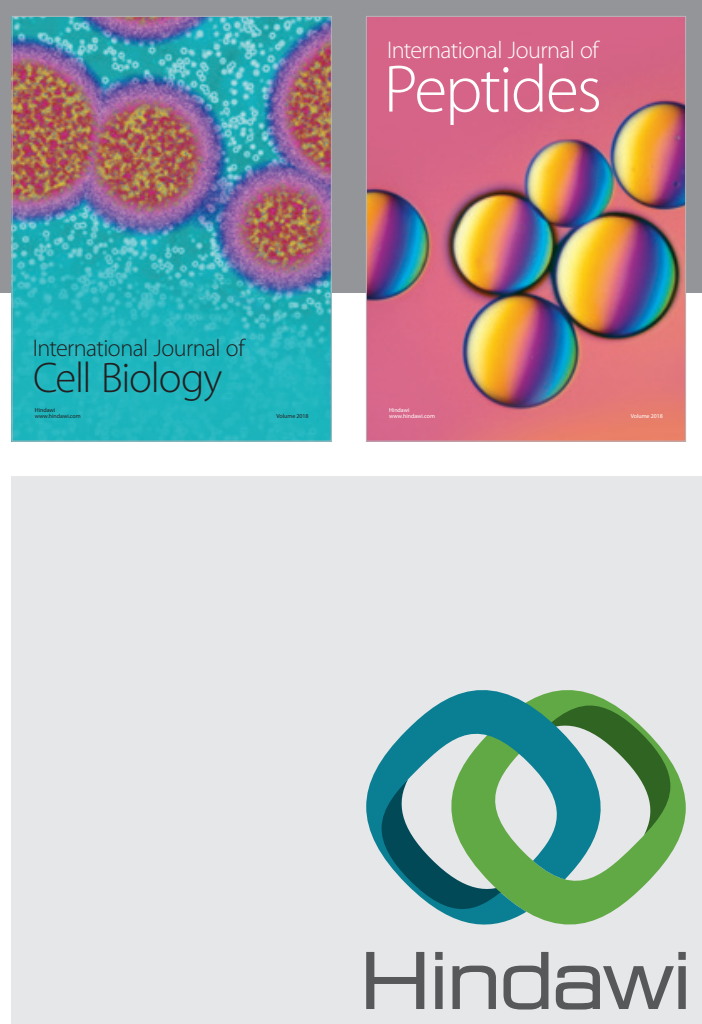

Submit your manuscripts at

www.hindawi.com

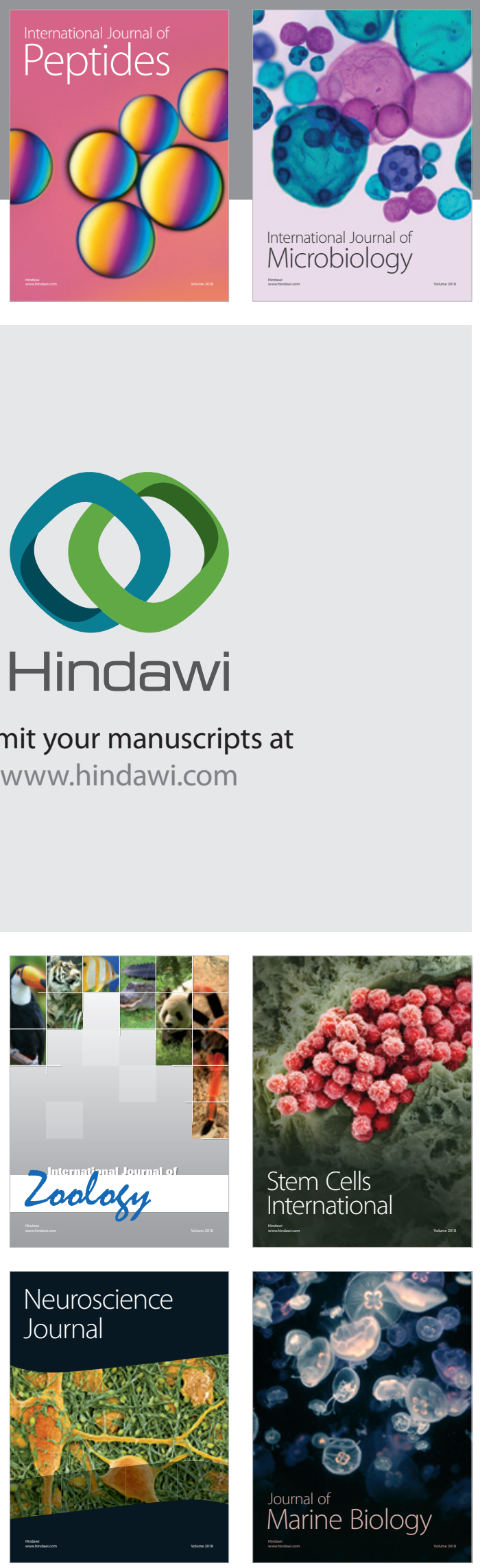
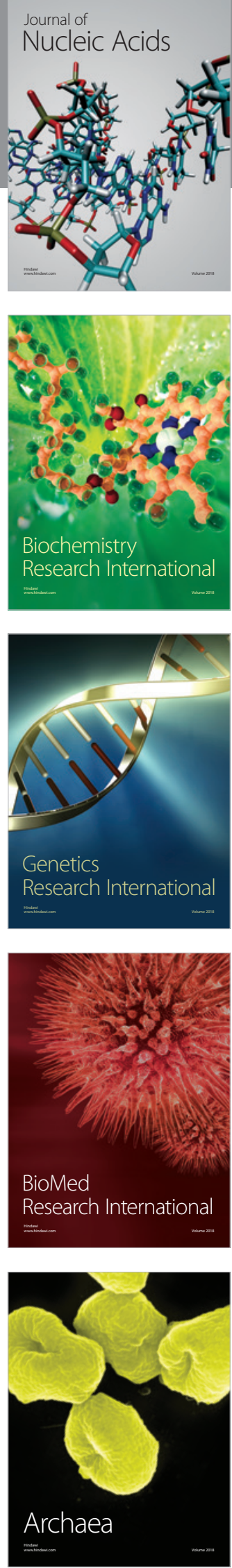